\title{
Estudo sobre grupos de terapia ocupacional para cuidadores de familiares de pacientes com esquizofrenia
}

\author{
Angélica da Silva Araujo ${ }^{a}$, Leonardo Martins Kebbe ${ }^{b}$ \\ ${ }^{a}$ Curso de Terapia Ocupacional, Faculdade de Medicina de Ribeirão Preto, \\ Universidade de São Paulo -USP, Ribeirão Preto, SP, Brasil
}

\begin{abstract}
Resumo: Objetivos: Conhecer os principais aspectos da experiência de cuidar de um familiar com esquizofrenia e discutir possíveis benefícios terapêuticos advindos da participação dos cuidadores em grupos de terapia ocupacional. Procedimentos metodológicos: Estudo qualitativo-descritivo, realizado em um ambulatório de saúde mental de um hospital geral localizado no interior do estado de São Paulo. A coleta de dados deu-se através de sessões de grupos de terapia ocupacional audiogravadas, das quais participaram dez familiares cuidadores de pacientes com esquizofrenia que fazem acompanhamento no ambulatório. Os dados foram analisados por meio da análise temática de conteúdo de Lawrence Bardin. Resultados: Os cuidadores de familiares com esquizofrenia encontram-se diariamente diante de dificuldades resultantes da convivência com o ente cuidado e dos comportamentos que ele apresenta. Os cuidadores ressaltaram a importância dos grupos como espaço em que foi possível entrar em contato com experiências de outras pessoas em situação similar, o que lhes possibilitou resolver dúvidas acerca da doença e dos cuidados oferecidos e também a oportunidade de refletirem sobre a importância de cuidarem de si mesmos. Conclusões: Há necessidade de novos estudos que tratem dessa temática e desenvolvam intervenções terapêuticas contínuas, oferecendo aos cuidadores escuta, compartilhamento de experiências e informações, visando instrumentalizá-los para que ofereçam um cuidado mais eficiente ao familiar com esquizofrenia e outros transtornos mentais. Ressalta-se a importância de avaliar essas intervenções.
\end{abstract}

Palavras-chave: Grupos, Terapia Ocupacional, Cuidadores, Esquizofrenia.

\section{Study on occupational therapy groups for caregivers of families with schizophrenia patients}

\begin{abstract}
Objective: To know the main aspects featuring the experience of caring for a family member who is schizophrenic and discuss the possible therapeutic benefits which arise from the participation of caregivers in occupational therapy groups. Methodological procedures: Qualitative-descriptive study, performed in a mental health ambulatory at a general hospital in the state of São Paulo. Data was collected through audio-recording in occupational therapy groups which counted on the participation of 10 family-caregivers of schizophrenic patients with follow-up treatment at this ambulatory. The data were analyzed through the thematic content analysis of Lawrence Bardin. Results: Caregivers of schizophrenic patients face daily difficulties arising from living together with their beloved ones and coping with their behaviors. These caregivers stress the importance of groups as a possible opportunity to have contact with other experiences of people under similar conditions, which not only enables them to clear doubts concerning the illness and the provided care, but also to reflect on the importance of taking care of themselves. Conclusions: There is great need for new studies that address this issue and develop continuous therapeutic interventions that offer caregivers the possibility to be heard about their experiences and to share information, aiming to prepare them to offer a more effective care for the schizophrenic family member and others with mental disorders. The importance of evaluating such interventions is therefore highlighted.
\end{abstract}

Keywords: Groups, Occupational Therapy, Caregivers, Schizophrenia. 


\section{Introdução}

Segundo Elkis e Meltzer (2007), cerca de 80 a $90 \%$ das pessoas diagnosticadas com esquizofrenia exibem disfunção social ou ocupacional em comparação ao que se esperaria delas a partir de seu nível funcional premórbido, tornando-se improdutivas financeiramente, tendo dificuldades na realização de tarefas domésticas e apresentando necessidade contínua de medicamentos. Para Tonelli e Alvarez (2009) e para Stuart e Laraia (2002), os relacionamentos interpessoais e a solução de problemas também figuram como dificuldades do cotidiano de pessoas com esquizofrenia.

Estudos (BANDEIRA; BARROSO, 2005; SOUZA FILHO et al., 2010) apontam a sobrecarga familiar como resultado da presença de uma pessoa com transtorno mental na família e do impacto consequente do cuidado que ela exige. Segundo Barroso, Bandeira e Nascimento (2007), a sobrecarga dos familiares cuidadores de pessoas com transtorno mental é caracterizada pela obrigatoriedade de atender às necessidades básicas delas, acompanhá-las frequentemente aos serviços de saúde, administrar sua medicação, coordenar suas atividades diárias, lidar com seus comportamentos problemáticos e seus episódios de crise, fornecer-lhes suporte social, arcar com gastos e superar as dificuldades dessas tarefas.

Tessler e Gamache (1996, p. 111), constataram que

O desempenho das tarefas de assistência ao ente adoecido, a supervisão dos seus comportamentos, os transtornos e as restriçóes que ocorrem na vida social e ocupacional dos familiares e o impacto financeiro, assim como os sentimentos advindos das preocupaçóes, a sensação de peso e de incômodo ao exercer algumas das funçóes do papel de cuidador assinalam algumas formas de sofrimento dele.

De acordo com o Ministério da Saúde (BRASIL, 2011), entre 2003 e 2010, a reestruturação da assistência hospitalar psiquiátrica aconteceu num processo coordenado e pactuado, possibilitando a redução do número de leitos e de hospitais psiquiátricos, com a construção progressiva de uma rede de atenção aberta, diversificada e comunitária, baseada nos Centros de Atenção Psicossocial (Caps), nas açôes de saúde mental na atenção básica, no Programa De Volta para Casa e nos programas de inclusão social pelo trabalho. Uma parcela de pessoas com transtornos mentais há longo tempo internada passou a contar com as Residências Terapêuticas e a beneficiar-se do Programa De Volta para Casa, criado em 2003.
Assim, os equipamentos e programas de saúde mental criados a partir da Reforma Psiquiátrica possibilitaram àqueles que têm transtorno mental receberem tratamento de caráter não restritivo, o que contribuiu para a maior proximidade e para o convívio cotidiano com seus familiares. Segundo Almeida et al. (2010), esse convívio tem gerado sofrimento para o familiar cuidador, especialmente pelo despreparo e pelo suporte social precário.

Conforme Pegoraro e Caldana (2006, p. 576), o [...] sofrimento dos cuidadores frente à problemática do transtorno mental na família e a tensão cotidiana vivida em seu lar tornam o cuidador alvo de atençáo dos serviços de saúde mental.

Observa-se que o sofrimento mental é compartilhado tanto pela pessoa com transtorno mental como pelo seu cuidador.

Em trabalho realizado por Souza Filho et al. (2010, p. 646), eles concluíram que

Intervençôes psicossociais deveriam ser implementadas pelos equipamentos de saúde mental com a finalidade de oferecer acolhimento, empatia e escuta terapêutica que levem o cuidador a contatar seus sentimentos, para que descubra novas possibilidades de existir e lidar com suas questóes. Acredita-se que essas intervenções possam contribuir para a redução do sofrimento do cuidador, melhorando sua qualidade de vida.

Observa-se nos trabalhos de Barroso, Bandeira e Nascimento (2007), Almeida et al. (2010), Pegoraro e Caldana (2006) e Souza Filho et al. (2010) indicações sobre a necessidade de implementaçáo de programas terapêuticos que possibilitem a reflexão compartilhada entre os cuidadores que vivem situaçôes de sofrimento.

A partir das questóes referentes à necessidade de atenção à saúde do cuidador, tais como registradas na literatura científica, buscou-se ofertar uma intervenção terapêutica com grupos de terapia ocupacional para a abordagem das experiências de cuidadores de familiares com esquizofrenia, atendidos em um ambulatório de saúde mental de um hospital geral situado em um município do interior do estado de São Paulo.

Segundo Ballarin (2007), grupos de terapia ocupacional podem ser definidos pela participaçáo de pessoas reunidas com um terapeuta ocupacional, em um mesmo espaço e horário, visando a realização de atividades. Segundo a autora, parte-se do princípio de que o fazer exerce um efeito terapêutico. Possibilita aos membros do grupo experimentarem novas 
formas de se relacionar e um fazer de forma inédita, favorecendo sentido e significado da açấo.

Maximino (2001) relata que entre os vários exemplos de atividades passíveis de serem realizadas nesses grupos encontram-se as atividades teatrais, gráficas, plásticas, artesanais, entre outras, aplicáveis conforme os objetivos delimitados para a abordagem grupal e a concepção teórico-metodológica do terapeuta ocupacional. Segundo consta na literatura (AGNOLON; SANTOS; ALMEIDA, 2006; BALLARIN, 2003; CUNHA; SANTOS, 2009), os objetivos dos grupos variam, podendo, a partir de um "fazer coletivo" almejar o compartilhamento de experiências, a interaçáo social, a expressáo de ideias e de sentimentos e a comunicação verbal e não verbal. Os grupos de terapia ocupacional podem também ser empregados para "[...] mobilizar, estimular, educar, treinar para o trabalho, treinar para a vida em sociedade, recriar e abordar problemas de relacionamento, conscientizar etc." (MAXIMINO, 2001, p. 19).

Maximino (2001) considera o grupo um conjunto de pessoas, porém destacando que não se trata de um conjunto qualquer, mas de um recorte: as pessoas que o integram devem ter características específicas que as incluam nesse coletivo, excluindo-se aquelas que não as possuem. Isto possibilita a formação do grupo, cujos participantes irão atuar frente a um objetivo compartilhado.

Acredita-se que o emprego de um dispositivo terapêutico (grupos de terapia ocupacional) no qual situaçóes vividas por cuidadores de pessoas com diagnóstico de esquizofrenia pudessem ser abordadas e compartilhadas com outras pessoas em situaçôes similares poderia contribuir para minorar o sofrimento desses cuidadores.

\section{Objetivos}

Conhecer os principais aspectos envolvidos na experiência de cuidar de um familiar com esquizofrenia; discutir possíveis benefícios terapêuticos advindos da participação dos cuidadores nos grupos de terapia ocupacional.

\section{Metodologia}

Tratou-se de um estudo qualitativo-descritivo, balizado pelos significados, valores, pelas motivaçóes, crenças e açóes dos familiares frente à pessoa com esquizofrenia sob seus cuidados.

Foram dez os participantes desse estudo (sete mulheres e três homens cuidadores de pessoas com esquizofrenia), com idade entre 45 e 72 anos, que acompanhavam o tratamento do familiar em um ambulatório de saúde mental de um hospital geral alocado em uma universidade pública em um município do interior do estado de São Paulo. Esse hospital pertence à rede pública do estado de São Paulo integrada ao Sistema Único de Saúde (SUS). Os participantes eram pais e mães dos usuários do ambulatório, sendo que nenhum deles recebia auxílio financeiro governamental pela doença. Dentre os sujeitos da pesquisa, três eram aposentados, uma era dona de casa, cinco eram autônomos e apenas um desempenhava atividades remuneradas com registro em carteira de trabalho. Quanto ao estado civil, quatro eram casados, quatro, viúvos e dois, divorciados. No que tange à escolaridade, um era analfabeto, seis possuíam ensino fundamental incompleto, dois, o ensino fundamental completo e um, o ensino superior completo.

O contato prévio e o convite aos familiares cuidadores foram feitos ao longo de dois meses, na sala de espera do ambulatório, quando esses cuidadores retornavam, com seus familiares, para a realização de consultas médicas.

A seleçấo deles seguiu os seguintes critérios: um cuidador por usuário; ser familiar de referência das pessoas diagnosticadas com esquizofrenia e que as acompanhava ao ambulatório; ter idade igual ou superior a 21 anos; não ter nenhum tipo de transtorno mental diagnosticado (informação obtida somente ao se questionar o cuidador, sem ter sido aplicado nenhum tipo de avaliaçáo diagnóstica); aceitar participar de cinco grupos coordenados pelos pesquisadores.

A pesquisa seguiu as determinaçóes da resoluçáo 196 (BRASIL, 1996) e foi aprovada, juntamente com o Termo de Consentimento Livre e Esclarecido, pelo Comitê de Ética em Pesquisa do Hospital das Clínicas da Faculdade de Medicina de Ribeirão Preto da Universidade de São Paulo (Processo HCRP n. 4894/2011).

Cada participante foi informado sobre os objetivos e as características da pesquisa, a garantia de confidencialidade e de anonimato e de que a não participação ou desistência da pesquisa náo acarretaria prejuízos e constrangimentos nem para ele, nem para o familiar em tratamento. Após esses esclarecimentos, os cuidadores que aceitaram participar da pesquisa assinaram o Termo de Consentimento Livre e Esclarecido.

A intervenção grupal deu-se por meio de cinco encontros grupais em uma sala do referido ambulatório. 
Os grupos de terapia ocupacional se reuniram semanalmente e cada encontro teve duração aproximada de uma hora. Esses grupos foram empregados como uma intervenção terapêutica direcionada à saúde do cuidador (objetivo primordial da pesquisa). Para isso, foram estipulados os seguintes objetivos terapêuticos: possibilitar a expressão das experiências que envolviam os cuidados ao familiar com transtorno mental; favorecer o compartilhamento dessas experiências entre os participantes; discutir estratégias de cuidados aos familiares com esquizofrenia e também aos próprios familiares cuidadores, visando melhorar as condiçôes de saúde deles e reestruturar, de acordo as possibilidades, a sua vida ocupacional.

Cada encontro foi planejado para a abordagem de assuntos específicos relacionados à temática "ser cuidador". Isso foi feito para se conhecer as experiências dos familiares que assumem o cuidado dos parentes com esquizofrenia (outro objetivo deste estudo).

Diante do exposto, além de constituírem dispositivos terapêuticos, os grupos de terapia ocupacional desta pesquisa também foram utilizados e explorados em seu potencial de fornecer dados. Para isto, os pesquisadores recorreram aos fundamentos acerca dos grupos de terapia ocupacional, buscando as interfaces entre os objetivos deles (antes descritos) com os objetivos gerais da abordagem metodológica de grupo focal.

Segundo Gatti (2005), o trabalho com grupos focais permite compreender ideias partilhadas por pessoas no dia a dia e os processos de construção da realidade pelos diferentes grupos sociais; compreender práticas cotidianas, açóes e reaçóes a eventos, comportamentos e atitudes, constituindo-se relevante técnica para o conhecimento de hábitos, valores, restriçóes, preconceitos, linguagens e simbologias prevalecentes sobre determinada questão por pessoas que partilham questóes em comum.

Enquanto intervenção terapêutica planejada para a abordagem e a exploração de assuntos predefinidos (sendo também o instrumento de coleta de dados deste estudo), os grupos de terapia ocupacional empregados foram baseados nas idéias de Hagedorn (2007), ou seja, um grupo dessa modalidade necessita do envolvimento simultâneo dos participantes na execução de atividades criativas ou produtivas, mediante propósito terapêutico estabelecido pelo terapeuta ocupacional. Levaram-se em conta, também, as observaçóes de Figlie (2004) apud Cunha e Santos (2009), sobre ser necessário para o terapeuta ocupacional conhecer as necessidades dos participantes do grupo, para poder selecionar adequadamente as atividades a serem realizadas. Aqui, esse conhecimento foi sendo desenvolvido ao longo do tempo, com base na literatura científica (primeiras aproximaçóes com a temática estudada) e com o posterior contato, durante dois meses, com os cuidadores que acompanhavam os familiares ao ambulatório.

Foram identificados os cinco grupos - siglas G1, G2, G3, G4 e G5 - e os cuidadores participantes - C1, C2, C3, C4, C5, C6, C7, C8, C9 e C10. Os temas previamente delimitados para cada grupo foram: 1) Apresentação; 2) Realização das atividades do cuidador e o cuidado com o familiar; 3) Dificuldades enfrentadas no dia a dia; 4) Lida com as dificuldades; 5) Perspectivas futuras. Atividades gráficas e expressivas foram utilizadas como disparadoras das discussóes, tendo como objetivos: facilitar o conhecimento mútuo entre os participantes; estimular que eles falassem de si e do familiar de quem cuidavam; favorecer reflexões sobre as atividades realizadas no dia a dia; verificar se o cotidiano do cuidador fora alterado devido ao cuidar oferecido ao familiar; possibilitar a expressão e a reflexão acerca das dificuldades sentidas pelos cuidadores no convívio cotidiano com o familiar; possibilitar o compartilhamento das estratégias que cada cuidador utilizava para lidar com as dificuldades causadas pela esquizofrenia; favorecer reflexôes acerca do futuro, tanto dos cuidadores quanto dos familiares com diagnóstico de esquizofrenia.

Os depoimentos dos participantes foram integralmente audiogravados. Foram feitas transcriçóes dos dados coletados de cada um dos grupos, coordenados por um docente da área de Terapia Ocupacional em Saúde Mental e cocoordenados por uma discente da instituiçáo universitária onde o docente atuava. Ao final de cada encontro eram discutidas as percepçóes gerais do coordenador e da cocoordenadora sobre o grupo, sendo algumas delas registradas em um diário de campo como estratégia para a reflexão sobre a forma de coordenação empregada.

São necessários alguns apontamentos sobre o papel dos coordenadores mencionados nessa intervenção grupal. Foi almejado proceder a intervençôes verbais somente quando os assuntos concernentes ao objeto de estudo deixassem de ser abordados pelos depoentes. Nesses momentos, os coordenadores deviam relembrar o grupo sobre a necessidade de retomar à temática em estudo.

Quando necessário, os coordenadores informaram aos cuidadores as características da esquizofrenia e também deram-lhes orientações verbais sobre possíveis estratégias para um melhor cuidado de si e do familiar 
(pois isso constituiu parte dos objetivos terapêuticos da intervençáo grupal). Houve momentos em que os cuidadores foram orientados sobre a necessidade de dividir as tarefas do cuidar com outras pessoas, sempre que possível, e também sobre a importância de se buscar um equilíbrio em suas atividades cotidianas, pois o cuidado com o familiar era uma preocupação central para os cuidadores estudados. Os cuidadores também fizeram sugestóes aos colegas de grupo sobre alguns desses aspectos. Ao término de cada encontro, os coordenadores fizeram sínteses verbais assinalando os pontos principais discutidos nos grupos de terapia ocupacional. Isso posto, concorda-se com Ballarin (2007, p. 40):

[...] o manejo grupal compreende todos os movimentos do coordenador dirigidos ao grupo na direção dos objetivos. Seriam, portanto, as intervençóes propriamente ditas do terapeuta ocupacional, expressas a partir do comunicar-se, colocar-se entre, mostrar-se atento, compreendendo a importância do estar e do fazer, buscando o significado da ação.

Para a análise dos dados obtidos, utilizou-se a análise temática de conteúdo de Bardin (2011), seguindo as seguintes etapas:

A) Pré-análise: As transcrições dos depoimentos coletados nos grupos foram lidas exaustivamente, o que possibilitou a operacionalização e a sistematização das ideias iniciais. Foram identificados, nos depoimentos dos participantes, trechos significativos referentes ao objeto deste estudo;

B) Exploraçáo do material: Os depoimentos coletados foram recortados e agrupados de acordo com a similaridade, formando categorias analíticas e unidades temáticas organizadas da forma exposta no Tabela 1:

Embora os grupos de terapia ocupacional tivessem sido planejados para a discussão de assuntos específicos para cada encontro, muitas questóes expressas pelos depoentes perpassaram todos os encontros. Como exemplo, o tema dificuldades enfrentadas no dia a dia foi objeto de discussão dos participantes no primeiro, segundo, terceiro, quarto e quinto grupos e não apenas no terceiro encontro, planejado para tal;

C) Tratamento dos resultados: Frente às unidades temáticas delineadas, buscou-se articulá-las à literatura sobre o objeto de estudo e proceder-se à discussão dos resultados. Nessa etapa, seguindo a técnica de análise temática de conteúdo, foi possível a proposição de inferências e de interpretação dos dados, de acordo com os objetivos previstos pela pesquisa. Foi possível, ainda, sugerir futuros estudos, como forma de responder às limitaçôes encontradas neste estudo.

\section{Resultados}

\subsection{Categoria analítica dificuldades enfrentadas pelos cuidadores}

Nessa categoria analítica foram identificadas as seguintes unidades temáticas: início da doença, períodos de crise e convívio diário do cuidador com o familiar.

\subsection{Início da doença}

O início da doença foi citado pelos familiares cuidadores como um período crítico, principalmente devido ao desconhecimento do que é a esquizofrenia, o que faz com que a doença gere medo: "Ele começou a ficar triste, a delirar. Quando eu fiquei sabendo que ele tinha esquizofrenia eu náo sabia o que era, tinha medo, não entendia" (C2, G1).

\subsection{Períodos de crise}

As situaçôes vivenciadas durante os períodos de crise foram assunto recorrente nos grupos,

Tabela 1. Categorias analíticas e unidades temáticas formadas.

\begin{tabular}{|c|c|}
\hline Categorias analíticas & Unidades temáticas \\
\hline 1. Dificuldades enfrentadas pelos cuidadores & $\begin{array}{l}\text { - Início da doença } \\
\text { - Períodos de crise } \\
\text { - Convívio diário do cuidador com o familiar }\end{array}$ \\
\hline 2. Benefícios da intervenção terapêutica grupal & $\begin{array}{l}\text { - Expressão de sentimentos } \\
\text { - Esclarecimento de dúvidas sobre a doença } \\
\text { - Aprendizagem sobre diferentes formas de cuidar } \\
\text { - Compartilhamento de experiências } \\
\text { - Disposição para cuidar }\end{array}$ \\
\hline
\end{tabular}


percebidas pelos cuidadores como sendo os momentos de maior sofrimento psíquico, tanto para si como para o familiar cuidado, sendo constante o medo de novas crises:

Ele dormia debaixo dos viadutos, com os mendigos, chegava de madrugada, sujo, fugia de casa, era violento. Subiu na laje do hospital, se machucou, foi amarrado (C5, G3).

Ele parava no meio do corredor da casa, em qualquer canto e ficava rodando. Dizia que uma voz falava para ele fazer aquilo $(\mathrm{C} 8, \mathrm{G} 3)$.

Eu tenho medo que de repente ele tenha uma crise. A gente sempre tem medo, pelo que passou (C2, G5).

\subsection{Convívio diário do cuidador com o familiar}

Como principais dificuldades envolvidas no cuidado diário com o familiar cuidado (filhos), os pais citaram a obstinação, o sono exacerbado, o modo como se alimentam e a insegurança que sentem: "Ele tem uma teimosia muito grande, difícil de lidar. Dorme muito, passa a vida dormindo" (C2, G3). "Meu filho tem muito medo, insegurança" (C5, G3).

Os sujeitos estudados ressaltaram a necessidade de estar o tempo todo atentos às atividades do filho de que cuidam, sendo a administração de medicamentos a atividade que exige maior supervisão: "A medicação é sob minha responsabilidade, eu não deixo com ele porque é muito, ele não vai dar conta” (C5, G3).

Segundo os cuidadores, a forma de se relacionar com os filhos tende a melhorar com o passar do tempo, sendo que o respeito é construído por ambas as partes envolvidas: "Fui aprendendo ao longo do tempo a me relacionar com ela, ter paciência. Hoje, essa relação é mais harmoniosa" (C6, G1). "Hoje nós combinamos muito bem. Ele me respeita, eu respeito ele" (C5, G4).

Embora os dados acima apontem para aspectos mais otimistas do convívio entre familiares e seus cuidadores, o sofrimento esteve presente nos depoimentos dos pais que, por vezes, deixaram de cuidar de si mesmos a fim de direcionar todos os esforços para o tratamento do filho: "A pessoa que cuida sofre igual, ou sofre até mais que a pessoa que está doente” (C7, G1). "Sofri muito. Fiz muita terapia” (C1, G3).

Muitas vezes o familiar tido como referência, ou seja, responsável constantemente pelo cuidado ao parente com esquizofrenia, vê-se obrigado a deixar de realizar atividades que realizaria regularmente caso não tivesse tal responsabilidade, como, por exemplo, atividades de lazer: "Não viajo porque se der algum problema na saúde dele longe daqui não sei o que fazes. Tenho medo" (C5, G2). "Se você tem uma pessoa que depende de cuidados, mesmo que você esteja longe, viajando, você está concentrada em casa" (C3, G2).

Em contrapartida, atividades de lazer passíveis de serem realizadas próximo ao familiar enfermo foram mencionadas pelos depoentes, especialmente objetivando uma pausa no cuidado oferecido ao ente adoecido: "Eu faço caminhada para melhorar a ansiedade e a preocupação. E costumo toda semana visitar os amigos" (C3, G2).

De acordo com os familiares, é importante reconhecer que mesmo a doença sendo a mesma - esquizofrenia -, cada pessoa diagnosticada tem suas particularidades, sendo que, por vezes, elas mesmas chamam a atenção dos pais para isso: "Ele fala assim: 'Cada um com se problema, deixa eu viver minha vida? Aceita eu do jeito que eu sou?’ (C1, G3). "Cada um tem um tipo de esquizofrenia diferente" (C5, G3).

Apesar de todas as dificuldades envolvidas nessa complexa tarefa, isto é, cuidar de uma pessoa com esquizofrenia, os familiares citaram que existem diversas formas de lidar com os comportamentos que os filhos apresentam, sendo que a paciência, a aceitação, a disciplina e a orientação são indispensáveis: "Eu tenho que lidar com muita paciência. Todos os dias é uma luta. Eu tenho que aceitar o que ele é, como ele é" (C5, G3). "Na primeira vez que ele encheu a boca de comida eu falei: 'Espera lá, isso não faz parte da sua educação'. Ele se reeducou" (C3, G3).

\subsection{Categoria analítica benefícios da intervenção terapêutica grupal}

Nessa categoria analítica foram identificadas as seguintes unidades temáticas: expressão de sentimentos; esclarecimento de dúvidas sobre a doença; aprendizagem sobre as diferentes formas de cuidar; compartilhamento de experiências; disposição para cuidar.

\subsection{Expressão de sentimentos}

De acordo com os sujeitos participantes, o grupo lhes propiciou um espaço em que foi possível falar o que não era possível compartilhar com seus outros familiares e também expressar seus sentimentos: 
"O que não tenho vontade de falar com minha família, posso falar aqui" (C1, G5). "Chegar aqui e falar sobre esse assunto ajuda bastante" (C3, G5). "A gente pode expressar nossos sentimentos" (C7, G5).

\subsection{Esclarecimento de dúvidas sobre a doença}

O grupo serviu como oportunidade para a expressão e resolução das dúvidas dos familiares concernentes à doença: "Eu me pergunto se os outros filhos não tomam banho direito, se têm preguiça. Se é normal, se alguém já passou por isso" (C1, G3). "Não sei se é da doença ou se é da personalidade dela não querer fazer as coisas" (C6, G2).

\subsection{Aprendizagem sobre as diferentes de formas de cuidar}

A aprendizagem sobre a doença e sobre diferentes formas de lidar com os filhos com esquizofrenia foi um dos resultados que a participação nos grupos possibilitou, segundo os familiares: "A gente vai aprendendo" (C5, G5). "Abre a mente da gente para um modo de continuar cuidando. Ajuda” (C2, G5).

\subsection{Compartilhamento de experiências}

O compartilhamento das experiências entre familiares que têm em comum a oferta de cuidados a um filho com esquizofrenia foi ressaltado pelos participantes como benéfico: "A gente acaba conhecendo a experiência que cada um tem" (C4, G5). "Cada um de nós aqui tem isso em comum" (C9, G1). "A gente acaba aprendendo um com o outro" (C7, G5).

\subsection{Disposição para cuidar}

Os cuidadores finalizam seu discurso ressaltando que a participação em grupos que abordam tais questôes resulta em disposição para a oferta de cuidados aos filhos com diagnóstico de esquizofrenia: "Dá mais ânimo para cuidar" (C4, G5).

\section{Discussão}

Devido aos sintomas da doença, é comum haver comprometimento nas habilidades necessárias para a realizaçáo de atividades como autocuidado, descanso, lazer, trabalho produtivo e participação social. Neste estudo, os familiares cuidadores de pessoas diagnosticadas com esquizofrenia referiram prejuízos dessa natureza.

O sono exacerbado que os entes cuidados apresentam foi tema recorrente nos depoimentos dos participantes deste estudo, pois limita o envolvimento do doente em atividades produtivas, como as laborais e educativas. Esse sono advém, em muitos casos, do uso de medicamentos para controle dos sintomas da doença, sendo um efeito adverso. Sua interrupção é inviável, posto ser a esquizofrenia uma doença crônica e que necessita de controle contínuo.

Segundo Sadock e Sadock (2007), a desorganização do comportamento e do pensamento são características marcantes da esquizofrenia. Os comportamentos problemáticos que as pessoas diagnosticadas apresentam (e que foram assinalados pelos cuidadores estudados) restringem a participação social por produzirem padróes comportamentais considerados socialmente inaceitáveis. É frequente que sintomas psicóticos interfiram no comportamento, mesmo quando a doença está controlada. De acordo com Peluso e Blay (2011), a maioria das pessoas associa esquizofrenia a periculosidade e violência, sendo ela um dos transtornos mentais avaliados mais negativamente pela população. Dessa forma, a participação social das pessoas com o referido diagnóstico se torna deficitária, uma vez que os outros tendem a se afastar por não compreenderem o que motiva o doente a apresentar tais comportamentos. Para Moll e Saeki (2009), a possibilidade de expansáo das relaçóes interpessoais de pessoas com esquizofrenia é remota devido ao estigma associado à doença. Devido a ele, os familiares mais próximos tendem a preencher essa necessidade relacional e psicossocial geralmente auxiliando os entes acometidos a realizarem atividades religiosas e de lazer. Embora seja uma forma de auxílio ao parente, suas atividades não são expandidas e nem exploradas.

As alterações da atenção, o retraimento social, a diminuição da motivação e da iniciativa, a anedonia e a alogia são importantes características que as pessoas com esquizofrenia apresentam e que impactam, de forma relevante, na realização de atividades laborais, visto que um bom desempenho nelas exige interesse constante, busca ativa e relacionamento adequado com outras pessoas. Segundo os sujeitos desta pesquisa, a insegurança e o medo também são sentimentos frequentes entre os familiares com esquizofrenia. Esses sentimentos, somados aos outros sintomas classificados como negativos, acabam por gerar perda da produtividade financeira das pessoas com a doença, uma vez que a maioria se encontra em idade produtiva, ficando dependentes de seus cuidadores nesse aspecto. 
Harvey e Bellack (2009) referem que o desempenho em atividades produtivas também é afetado por aspectos sociais, dentre os quais novamente se destaca o estigma. Os autores apontam que, muitas vezes, a pessoa diagnosticada com esquizofrenia se encontra motivada e com habilidades para trabalhar, mas é excluída do mercado pelos empregadores e/ou pelo sistema econômico, que favorecem aqueles com histórico exitoso de trabalho. Além disso, Silva et al. (2011) apontam que o fato de a doença começar principalmente na juventude faz com que as pessoas acometidas não tenham oportunidade de concluir seus estudos, gerando obstáculos para conseguirem melhores empregos e salários.

Neste estudo, nenhum dos familiares cuidados pelos participantes recebia auxílio financeiro governamental nem exercia atividades remuneradas (mesmo aqueles que se encontravam aptos para exercê-las), acarretando aos cuidadores maior responsabilidade financeira e gerando sentimentos de impotência naqueles com diagnóstico de esquizofrenia.

Observa-se que os aspectos clínicos e o tratamento medicamentoso da pessoa com esquizofrenia interferem na sua vida ocupacional (neste estudo, no sono, na participaçáo social, no trabalho, no lazer e na administração de medicamentos). Porém, o estigma conferido à doença deve ser considerado por interferir também na aceitação da pessoa nos diversos contextos sócio-ocupacionais, o que limita a participaçáo social. Nesse sentido, a pessoa acometida não deve ser considerada somente em uma perspectiva reducionista e individualizante (o que ocorre quando se considera somente o diagnóstico psiquiátrico), pois os problemas relacionados à exclusão social que enfrenta também se originam e são reproduzidos na sociedade.

Isso se alinha às questões discutidas por Lussi, Pereira e Pereira Junior (2006), que assinalam que o caráter estigmatizante do diagnóstico psiquiátrico contribui para a ineficácia das terapêuticas dos equipamentos de saúde mental, pois, per se, o diagnóstico desconsidera o contexto real de vida do paciente e de sua história pessoal, aspectos psicossociais que constituem potenciais determinantes do sofrimento mental e das possibilidades de enfrentamento. Restrita ao diagnóstico e por ele rotulada, a pessoa é impossibilitada de fazer escolhas e de efetuar trocas nos contextos sociais, o que dificulta a atuação do cuidador, por ele sofrer com o paciente os impactos da exclusão social.

Conforme apontado na literatura (BARROSO; BANDEIRA; NASCIMENTO, 2007; BANDEIRA; BARROSO, 2005; BANDEIRA; CALZAVARA; CASTRO, 2008; SOUZA FILHO et al., 2010) e observado nos relatos dos sujeitos pesquisados, é comum haver despreparo do familiar cuidador para assumir o cuidado de forma adequada, o que gera nele dificuldades especialmente durante os episódios de crise do familiar adoecido, mas também no dia a dia, quando a doença está controlada por medicamentos e/ou por outras intervençôes terapêuticas.

Frente ao desconhecimento dos sintomas da doença e de sua cronicidade, especialmente no início da doença ou mesmo após, nos episódios de crise, os cuidadores estudados tiveram seu sofrimento intensificado. $O$ convívio com a pessoa com esquizofrenia é vivido com incerteza e insegurança: quando os cuidadores atentam para a possibilidade de enfrentarem novos períodos de crise, surgem sentimentos como o medo; as possibilidades de convívio entre o cuidador e o familiar parecem aumentar na remissão dos sintomas, o que é, reconhecidamente, favorecido pelo caráter não restritivo dos novos equipamentos de saúde mental, tal qual o ambulatório onde foi realizado este estudo.

Assim, as perspectivas futuras dos cuidadores aqui estudados são vislumbradas com angústia, diante da insegurança e do medo de que os entes cuidados entrem em crise, de que o tratamento medicamentoso deixe de ser eficaz e, também, do futuro dos filhos, visto que esses pais, em algum momento, não estarão mais presentes. Essas angústias se fundamentam em situaçóes vividas pelos cuidadores, que já presenciaram o sofrimento do filho experimentando, junto dele, preconceitos por parte do restante da família, de amigos e de desconhecidos.

Considerando os cuidadores estudados, três deles são aposentados e um exerce tarefas somente no lar. Isso sugere maior permanência desses cuidadores em casa, junto de seus familiares com diagnóstico psiquiátrico - esse convívio pode aumentar ou diminuir o sofrimento do cuidador, segundo a forma como se encontram as pessoas de que cuidam, ou seja, sintomáticas ou assintomáticas. A isso soma-se o fato de sete dentre os dez participantes deste estudo serem mulheres, o que indica a interferência de questóes culturais (como de gênero), que as levariam a assumir totalmente os cuidados dos filhos e, portanto, depararem-se com dificuldades para compartilhar o cuidado (e as intercorrências a ele associadas) com outros membros da família.

Desse modo, o investimento em atividades de autocuidado e de lazer pode ser prejudicado pois, como apontam os resultados, o tempo despendido nos cuidados dos filhos e no custo emocional decorrente limitam aspectos relevantes da participação social e demais atividades dos cuidadores.

O estado civil é outro aspecto a ser considerado: dentre os participantes do estudo, quatro são 
viúvos e dois divorciados, dados que sugerem que os cuidadores realizam suas tarefas sem o auxílio de cônjuges.

Outro aspecto merecedor de atenção refere-se ao grau de escolaridade dos cuidadores estudados: entre dez, um era analfabeto, seis cursaram ensino fundamental de forma incompleta, dois completaram o ensino fundamental e um terminou o ensino superior. Assim, a maior parte dos sujeitos (sete cuidadores) poderia apresentar dificuldades nas tarefas de cuidado pois, segundo Miguel, Figueira e Nardi (2010), Dahdah (2012) e Sousa et al. (2012), o grau de escolaridade, se deficitário ou incompleto, vincula-se diretamente às dificuldades de compreensão para a realizaçáo de atividades como administração correta de medicação, leitura de bulas, orientaçóes nutricionais, ocupacionais e, ainda, no modo como os familiares percebem a doença e agem sobre ela.

Neste estudo, os dados apontaram o contrário, pois os cuidados foram despendidos pelos cuidadores independente do seu nível de instrução, de acordo com as possibilidades individuais e um repertório prévio de conhecimentos de cada cuidador. Acresce-se que, na eclosão da crise esquizofrênica, os cuidadores podem intensificar sua ansiedade e isso também poderia dificultar a compreensão das orientaçóes feitas por profissionais de saúde, acarretando problemas na efetivaçáo dos cuidados no domicílio e na comunidade. Embora houvesse momentos de ansiedade, insegurança e medo, conforme apontaram os dados, o fato de os cuidadores acompanharem os familiares, sistematicamente, ao tratamento em ambulatório sugere que essa modalidade de seguimento (ambulatorial) oferece um ponto de apoio aos usuários e a seus cuidadores, pois o contato regular deles com os profissionais de saúde pode prover o apoio emocional necessário.

Frente ao exposto, diversos aspectos da vida dos cuidadores se cruzam e, associados às condiçóes crônicas da esquizofrenia, podem aumentar as experiências de sofrimento do cuidador, o que aponta para as múltiplas questóes disparadoras desse sofrimento. Ainda assim, os participantes do estudo referiram enfrentar as dificuldades resultantes dos cuidados que assumiram, o que indica um aspecto positivo e saudável relacionado ao papel de cuidador.

Reitera-se, diante das questóes especialmente apontadas sobre as dificuldades de cuidar e o sofrimento decorrente, a necessidade de intervençóes terapêuticas voltadas para a saúde do cuidador, para que esse possa atenuar seu sofrimento e repensar sua vida ocupacional, além de aprender estratégias adequadas ao cuidado do familiar.

Considerando a intervenção terapêutica empregada neste estudo (grupos de terapia ocupacional), concorda-se com Lussi, Pereira e Pereira Júnior
(2006), ou seja, que a ampliação da rede social constitui estratégia para o aumento das habilidades da pessoa (neste estudo, do cuidador), visando ao enfrentamento das dificuldades vividas.

Constata-se que a valorização dos cuidadores nos grupos de terapia ocupacional dos quais participaram, neste estudo, assentou-se na possibilidade que tiveram de expressar ideias, sentimentos e ações, oportunidade que, em outros contextos de vida, não teriam e que também foi facilitada pela identificação mútua que estabeleceram.

A participação dos cuidadores sujeitos desta pesquisa em grupos estruturados para a discussão de temas específicos operacionalizadas por meio de atividades gráficas e expressivas mostrou-se estratégia relevante para o compartilhamento das experiências entre os participantes, possibilitando-lhes a expressão de sentimentos.

Tais atividades foram propulsoras e facilitadoras das discussóes grupais, propiciando trocas de experiências cognitivas, afetivas e, também, divulgação das açôes empreendidas no cuidado prestado ao ente com transtorno mental, como orientaçóes relacionadas à educação dos filhos (por exemplo, formas socialmente adequadas para se alimentarem, no controle da medicação e nas atividades de autocuidado) e ao convívio que favoreceram aos cuidadores o entendimento de que, embora lidem com familiares com o mesmo diagnóstico (esquizofrenia), cada um deles apresenta modos singulares de se expressar, de lidar com a doença e, sobretudo, de buscar apoio, respeito e afeto por parte de seu cuidador.

Outras açóes expostas nos grupos, realizadas pelos cuidadores e visando a um cuidado possível de si mesmos, foram atividades físicas (caminhadas) e outras de caráter social (visitas a amigos), o que pode contribuir para o alívio do sofrimento a que estão submetidos e também para a manutenção de relaçóes interpessoais que lhes assegurem suporte social.

Considera-se que o compartilhamento de experiências (facilitado pelas atividades planejadas pelos coordenadores) reiterou à abordagem grupal o caráter terapêutico. Como exemplo, no grupo em que houve a abordagem do tema dificuldades, elas foram escritas em balóes coloridos e os coordenadores orientaram os cuidadores a estourá-los logo após. Isso possibilitou representarem as dificuldades do cuidar e dos sentimentos a elas associados. Os participantes puderam, inicialmente, transpor tais questóes, entáo subjetivas, para algo concreto, o que facilitou a identificação e a discussão de questôes semelhantes relacionadas ao cuidar. Com isso, os sujeitos estudados passaram à condiçấo de partícipes do grupo e essa possibilidade de participar de algo 
coletivo pôde atenuar o sentimento de experimentar de forma individual os problemas vividos enquanto cuidadores.

Assim sendo, as características terapêuticas da intervenção grupal encontram respaldo em Cunha e Santos (2009), que assinalam os diversos objetivos terapêuticos dos grupos de terapia ocupacional, entre os quais: expressar ideias e sentimentos; possibilitar reflexôes; organizar experiências verbais e visuais; compartilhar experiências e dificuldades; identificar a universalidade das experiências vividas e a singularidade dos indivíduos e aprender a relacionar-se com os membros do grupo.

A abordagem grupal realizada nessa pesquisa propiciou universalidade, citada por Yalom e Yalom (2006), aos membros do grupo, pois atuou na ressignificação da percepção dos cuidadores de não estarem desamparados, ao reconhecerem que os problemas vividos com seus familiares eram comuns a todos os colegas de grupo, o que possivelmente lhes ofereceu algum alívio.

Outros aspectos terapêuticos da abordagem grupal, também definidos por Yalom e Yalom (2006), podem ser percebidos nos depoimentos dos cuidadores: o oferecimento de informaçóes, que ocorre sempre que o aconselhamento ou a orientaçáo direta sobre problemas de vida são oferecidos pelo líder ou pelos participantes do grupo. Observou-se o oferecimento de informaçóes nos relatos daqueles que aludiram à importância da participação no grupo de terapia ocupacional pelo seu potencial de esclarecer dúvidas sobre a esquizofrenia e também sobre as formas consideradas adequadas, para que eles pudessem lidar com os comportamentos problemáticos que os filhos apresentam. A instruçáo didática, na qual técnicas de redução do estresse e de relaxamento são ensinadas aos membros do grupo, integra o oferecimento de informaçóes, o que pôde ser observado quando alguns dos participantes ressaltaram a importância da atividade física (caminhada) e da visita a amigos para a melhora de sua saúde, desencadeando reflexôes em outros membros do grupo acerca dessa estratégia de cuidado próprio.

Os momentos nos quais os cuidadores ressaltaram a importância do compartilhamento de experiências cotidianas com o filho com esquizofrenia foram propícios para a coesão grupal, pois possibilitaram a expressão de temas que interessavam a todos (YALOM; YALOM, 2006; CUNHA; SANTOS, 2009). Aqui atenta-se para outro aspecto terapêutico grupal, ou seja, os momentos em que o grupo atuou como "caixa de ressonância", expressão usada por Ballarin (2003) e por Maximino (2001), a saber, quando uma ação ou expressão verbal do coordenador ou dos participantes em relação a um dos membros do grupo alcança os demais, ampliando o potencial interventivo do grupo, tornando-o também um campo confiável e facilitador para a exploração das diferentes questôes vividas.

A catarse ou a ventilação das emoçôes, citada por Yalom e Yalom (2006), foi percebida nos grupos na medida em que o familiar relatava a outros as dificuldades enfrentadas no seu dia a dia e os participantes manifestavam suas emoçóes através de choro e de relatos que expressavam raiva da doença e medo de novas crises. Essas emoçóes foram acolhidas pelos coordenadores e pelos membros do grupo. O altruísmo foi observado quando os familiares sentiam-se úteis, ao perceber que seus relatos auxiliavam os demais participantes a enriquecerem sua bagagem para a oferta de cuidados.

No que tange ao fator terapêutico denominado aprendizagem interpessoal por Yalom e Yalom (2006), tanto os coordenadores do grupo como as atividades atuaram como facilitadores dessa aprendizagem em grupo, criando situaçóes propícias para o aprendizado conjunto acerca da doença e das formas de lidar com os filhos. Ao longo dos grupos de terapia ocupacional, os participantes mostraram-se dispostos a oferecer ajuda e a trocar experiências, criando um circuito de apoio baseado em dar e receber.

Segundo Cunha e Santos (2009), grupos compostos por pessoas com necessidades semelhantes tendem ao apoio mútuo, sugerindo soluçôes para os problemas compartilhados, favorecendo aos integrantes a aprendizagem com o feedback dos outros, assim como o desenvolvimento de recursos e de habilidades. Neste estudo, considerando-se os dados obtidos, esses aspectos puderam ser observados: houve auxílio mútuo e sugestóes para o cuidado dos familiares e do próprio cuidador, o que possibilitou aos partícipes ampliarem seu repertório de estratégias para tais tarefas.

Dahdah (2012, p. 79) aponta que

[...] o cuidado ofertado à pessoa não deve somente ser avaliado ou considerado em seus aspectos negativos, pois muitas vezes esses reconhecem e redimensionam seu papel enquanto cuidador, considerando-se imprescindível na ajuda ao ente cuidado e tornando-se referência no grupo familiar, o que resultaria em benefícios psicológicos.

Embora esses benefícios psicológicos possam confortar o cuidador, isso deve ser analisado com cautela, pois esse conforto pode ser momentâneo caso haja uma responsabilização total pelos cuidados do familiar com transtorno mental. No decorrer do tempo, devido o acúmulo de tarefas, o cuidador poderia apresentar sofrimento físico e mental. 
Ressalta-se que, nesta pesquisa, a forma de se relacionar com os filhos constitui-se em um importante desafio para os cuidadores, que no início da doença tendem a apresentar mais dificuldade em compreender os modos de agir, o que resulta em sofrimento de ambas as partes envolvidas. Segundo os familiares, essa forma de se relacionar melhora com o passar do tempo e com o controle dos sintomas da doença, ao passo que os acompanhamentos médico e terapêutico fornecem-lhes subsídios para entender as particularidades da esquizofrenia e o que ela pode causar, sendo constantemente necessário paciência com o ente cuidado e aceitaçáo da situaçáo na qual ele se encontra. É essencial trabalhar essa aceitação (tarefa longa e difícil) junto ao cuidador para que esse processo se dê da melhor maneira possível.

\section{Considerações finais}

A tarefa de cuidar de uma pessoa com esquizofrenia é complexa e exige forte envolvimento e disponibilidade dos responsáveis pelos cuidados.

Os depoimentos colhidos nos grupos de terapia ocupacional, com os familiares cuidadores, possibilitaram observar que eles, diariamente, veem-se diante de dificuldades resultantes da convivência com os entes com esquizofrenia e com os comportamentos que eles apresentam. Foi também possível observar a valorização que esses cuidadores conferiram aos grupos, pela possibilidade de entrarem em contato com as experiências de pessoas em situaçóes similares, o que lhes facilitou resolver dúvidas acerca da doença e dos cuidados oferecidos. Destaca-se, ainda, que grupos de terapia ocupacional operacionalizados por meio de diferentes atividades podem constituir relevante instrumental para a coleta de dados em pesquisa, dadas as suas aproximaçóes com os grupos focais.

Faz-se necessária a implantação de estratégias que tenham como foco os cuidados aos cuidadores, especialmente àqueles que cuidam de pessoas com transtornos mentais graves e persistentes, como a esquizofrenia, de modo a lhes oportunizar a reflexão compartilhada sobre os possíveis modos de cuidar de si e do outro, expor suas dificuldades e seus afetos. Os aspectos positivos envolvidos no papel de cuidador também devem ser valorizados nas estratégias interventivas. Destaca-se a importância de avaliarem-se as intervençóes realizadas com os cuidadores.

Embora a intervenção grupal tivesse como um de seus objetivos a reestruturação possível da vida ocupacional dos cuidadores, houve limitaçóes para que isso ocorresse: talvez pela forma de coordenação adotada, no sentido de buscar que os participantes se ativessem à discussão de temas predeterminados, isso tenha constituído obstáculo para a abordagem e para a orientaçáo a contento da vida ocupacional dos cuidadores. O número limitado dos encontros (cinco) também pode ter contribuído para essa limitação. Assim sendo, sugere-se que futuros estudos abordem mais amplamente tais aspectos,tão caros à saúde e à qualidade de vida do cuidador.

É necessário, ainda, que estratégias de intervenção contínuas sejam desenvolvidas nos diferentes equipamentos de saúde mental, para que possam instrumentalizar o familiar cuidador para um cuidado eficaz de si e da pessoa com transtorno mental, no domicílio e no território, com a finalidade de minorar a sobrecarga por que passam no exercício de suas tarefas de cuidar e para que possam ressignificar suas experiências.

\section{Referências}

AGNOLON, M. C.; SANTOS, S. S.; ALMEIDA, M. H. M. Grupo de orientação postural a idosos com dor osteomuscular: estabelecendo relaçóes entre teoria e prática. Revista de Terapia Ocupacional da USP, Sáo Paulo, v. 17, n. 2, p. 80-86, 2006. http:10.11606/issn.2238-6149. v17i2p80-86

ALMEIDA, M. M.; SCHAL, V. T.; MARTINS, A. M.; MODENA, C. M. A sobrecarga de cuidadores de pacientes com esquizofrenia. Revista de Psiquiatria do Rio Grande do Sul, Porto Alegre, v. 32, n. 3, p. 73-79, 2010. http://dx.doi.org/10.1590/S0101-81082010005000003

BALLARIN, M. L. G. S. Abordagens grupais. In: CAVALCANTI, A; GALVÃO, C. Terapia Ocupacional: Fundamentaçáo \& Prática. Rio de janeiro: Guanabara Koogan, 2007. p. 38-43.

BALLARIN, M. L. G. S. Algumas reflexōes sobre grupos de atividades em Terapia Ocupacional. In: PADUA, E. M. M.; MAGALHĀES, L. V. (Orgs.). Terapia Ocupacional: Teoria e Prática. Campinas: Papirus, 2003. p. 63-76.

BANDEIRA, M.; BARROSO, S. Sobrecarga das famílias de pacientes psiquiátricos. Jornal Brasileiro de Psiquiatria, Rio de Janeiro, v. 54, n. 1, p. 34-46, 2005.

BANDEIRA, M.; CALZAVARA, M. G. P.; CASTRO, I. Estudo de validade da escala de sobrecarga de familiares cuidadores de pacientes psiquiátricos. Jornal Brasileiro de Psiquiatria, Rio de Janeiro, v. 57, n. 2, p. 98-104, 2008.

BARDIN, L. Análise de conteúdo. Tradução de Luís Antero Reto; Augusto Pinheiro. São Paulo: Edições 70, 2011.

BARROSO, S. M.; BANDEIRA, M.; NASCIMENTO, E. Sobrecarga de familiares de pacientes psiquiátricos atendidos na rede pública. Revista de Psiquiatria Clínica, Sáo Paulo, v. 34, n. 6, p. 270-277, 2007.

BRASIL. Ministério da Saúde. Conselho Nacional de Saúde. Diretrizes e Normas Regulamentadoras de Pesquisa 
Envolvendo Seres Humanos. Resolução 196/96. Brasília: Ministério da Saúde, 1996.

BRASIL. Ministério da Saúde. Secretaria de Atenção à Saúde. DAPES. Coordenação Geral de Saúde Mental, Álcool e Outras Drogas. Saúde Mental no SUS: as novas fronteiras da Reforma Psiquiátrica. Relatório de Gestão 2007-2010. Brasília: Ministério da Saúde, 2011.

CUNHA, A. C. F.; SANTOS, T. F. A utilização do grupo como recurso terapêutico no processo da Terapia Ocupacional com clientes com transtornos psicóticos: apontamentos bibliográficos. Cadernos de Terapia Ocupacional da UFSCar, São Carlos, v. 17, n. 2, p. 133-146, 2009.

DAHDAH, D. F. Enfrentamento, papéis ocupacionais e a tarefa de cuidar de um idoso dependente. 2012. $100 \mathrm{f}$. Dissertação (Mestrado em Enfermagem Psiquiátrica)Escola de Enfermagem de Ribeirão Preto, Universidade de São Paulo, Ribeirão Preto, 2012.

ELKIS, H.; MELTZER, H. Y. Esquizofrenia refratária. Revista Brasileira de Psiquiatria, São Paulo, v. 29, p. S41-S47, 2007. http://dx.doi.org/10.1590/ S1516-44462007000600002

GATTI, B. A. Grupo focal na pesquisa em Ciências Sociais e Humanas. Brasília: Liber Livro Editora, 2005.

HAGEDORN, R. Ferramentas para a prática em Terapia Ocupacional: uma abordagem estruturada aos conhecimentos e processos centrais. São Paulo: Roca, 2007.

HARVEY, P. D.; BELLACK, A. S. Toward a terminology for functional recovery in schizophrenia: is functional remission a viable concept? Schizophrenia Bull, Oxford, v. 35, n. 2, p. 300-306, 2009. PMid:19126634 PMCid:PMC2659311. http://dx.doi.org/10.1093/schbul/ sbn 171

LUSSI, I. A. O.; PEREIRA, M. A. O.; PEREIRA JUNIOR, A. A Proposta de Reabilitaçáo Psicossocial de Saraceno: Um Modelo de Auto-Organização? Revista Latino Americana de Enfermagem, Ribeirão Preto, v. 14, n. 3, p. 448-456, 2006. http://dx.doi.org/10.1590/ S0104-11692006000300021

MAXIMINO, V. S. Grupos de atividades com pacientes psicóticos. São José dos Campos: Univap, 2001.

MIGUEL, M. E. G. B.; FIGUEIRA, M. O.; NARDI, E. F. R. Perfil dos cuidadores familiares de idosos dependentes de uma unidade básica de saúde. Revista F@pciência, Apucarana, v. 6, n. 14, p. 118-127, 2010.
MOLL, M. F.; SAEKI, T. A Vida Social de Pessoas com Diagnóstico de Esquizofrenia Usuárias de um Centro de Atenção Psicossocial. Revista Latino Americana de Enfermagem, Ribeirão Preto, v. 17, n. 6, 2009. http:// dx.doi.org/10.1590/S0104-11692009000600011

PEGORARO, R. F.; CALDANA, R. H. L. Sobrecarga de familiares de usuários de um Centro de Atenção Psicossocial. Revista Psicologia em Estudo, Maringá, v. 11, n. 3, p. 569-577, 2006.

PELUSO, E. T. P.; BLAY, S. L. Public stigma and schizophrenia in São Paulo city. Revista Brasileira de Psiquiatria, São Paulo, v. 33, n. 2, p. 130-136, 2011. http://dx.doi.org/10.1590/S1516-44462010005000004

SADOCK, B. J.; SADOCK, V. A. Compêndio de Psiquiatria: ciências do comportamento e psiquiatria clínica. 9. ed. Porto Alegre: Artmed, 2007.

SILVA, T. F. C. et al. Quality of life assessment of patients with schizophrenic spectrum disorders from Psychosocial Care Centers. Jornal Brasileiro de Psiquiatria, Rio de Janeiro, v. 60, n. 2, p. 91-98, 2011. http://dx.doi. org/10.1590/S0047-20852011000200004

SOUZA FILHO, M. D. et al. Avaliação da sobrecarga em familiares cuidadores de pacientes esquizofrênicos adultos. Revista Psicologia em Estudo, Maringá, v. 15, n. 3, p. 639-647, 2010.

SOUSA, S. et al. Stigmatizing attitudes in relatives of people with schizophrenia: a study using the Attribution Questionnaire AQ-27. Trends Psychiatry Psychotherapy, Rio Grande do Sul, v. 34, n. 4, p. 186-197, 2012. http:// dx.doi.org/10.1590/S2237-60892012000400004

STUART, G. W.; LARAIA, M. T. Enfermagem Psiquiátrica. 4 ed. Rio de Janeiro: Reichmann \& Affonso Editores, 2002

TESSLER, R. C.; GAMACHE, G. M. The Family Burden Interview Schedule - Short Form (FBIS/SF). In: SEDERER, L.; DICKEY, B. (Eds.). Outcome Assessment in Clinical Practice. Baltimore: Williams \& Williams, 1996. p. 110-112.

TONELLI, H.; ALVAREZ, C. E. Cognição social na esquizofrenia: um enfoque em habilidades teoria da mente. Revista de Psiquiatria do Rio Grande do Sul, Porto alegre, v. 31, n. 3, suppl., 2009. http://dx.doi.org/10.1590/ S0101-81082009000400005

YALOM, I. D; YALOM, M. L. Psicoterapia de grupo: teoria e prática. Traduçáo de Ronaldo Cataldo Costa. 5. ed. Porto Alegre: Artemed, 2006.

\section{Contribuição dos Autores}

Angélica Araújo é responsável pela concepção e redação do texto, desenvolvimento da discussão dos dados, organização, análise de fontes e revisão. Leonardo Kebbe é responsável pela concepção do estudo e do texto, desenvolvimento da discussão dos dados, redação do texto. 